\title{
A case report of psychiatric symptoms following direct-acting antiviral and ribavirin combination therapy for chronic hepatitis $C$ in a patient with innate anxiety
}

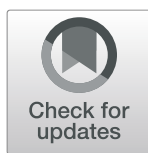

Akira Sakamaki ${ }^{{ }^{*}}$ D, Kenya Kamimura', Naoki Fukui ${ }^{2}$, Haruka Watanabe², Norihiro Sakai ${ }^{1}$, Kentaro Tominaga ${ }^{1}$, Kenichi Mizuno', Masaaki Takamura', Hirokazu Kawai ${ }^{1}$, Takuro Sugai ${ }^{2}$, Satoshi Yamagiwa' ${ }^{1}$, Toshiyuki Someya ${ }^{2}$ and Shuji Terai ${ }^{1}$

\begin{abstract}
Background: Direct-acting antivirals (DAAs) result in a highly sustained virological response rate and better patient tolerance. However, this therapeutic approach may, on rare occasions, give rise to psychiatric symptoms. We describe a case requiring discontinuation of DAA and ribavirin combination therapy due to psychiatric symptoms in a patient with congenital anxious personality traits. The information summarized here will be helpful to physicians treating chronic hepatitis $C$ virus (HCV) infection in patients with underlying psychiatric problems.

Case presentation: A 57-year-old Japanese woman diagnosed with chronic HCV infection was prescribed DAA and ribavirin combination therapy. She had a history of mild innate anxiety and development of psychiatric symptoms due to interferon (IFN) therapy 8 years prior, which subsided with discontinuation of the therapy. Similar psychiatric symptoms such as enervation, palpitations, an episode of hyperventilation, and consciousness disturbances with myotonia were observed after the administration of the antiviral agents. No abnormal findings related to her symptoms were observed on laboratory or imaging results. Psychiatrists diagnosed the patient as having a somatization disorder induced by the antiviral agents on the basis of innate anxiety. After the discontinuation of therapy, her symptoms gradually improved.

Conclusions: Although DAAs were not causative factors for psychiatric symptoms in phase 3 studies, a postmarketing study reported psychiatric symptoms such as depression in patients with underlying psychiatric problems. Our case suggests psychiatric symptoms might worsen after DAA and ribavirin administration in patients with underlying psychiatric disorders, and therefore, close monitoring is necessary for these patients, especially if they have a history of psychiatric symptoms after IFN.
\end{abstract}

Keywords: Interferon, Direct-acting antiviral, Psychiatric symptom, Case report

\footnotetext{
* Correspondence: saka-a@med.niigata-u.ac.jp

${ }^{1}$ Division of Gastroenterology and Hepatology, Graduate School of Medical and Dental Sciences, Niigata University, 1-757 Asahimachidori, Chuo-ku, Niigata 951-8510, Japan

Full list of author information is available at the end of the article
}

(c) The Author(s). 2019 Open Access This article is distributed under the terms of the Creative Commons Attribution 4.0 International License (http://creativecommons.org/licenses/by/4.0/), which permits unrestricted use, distribution, and reproduction in any medium, provided you give appropriate credit to the original author(s) and the source, provide a link to the Creative Commons license, and indicate if changes were made. The Creative Commons Public Domain Dedication waiver (http://creativecommons.org/publicdomain/zero/1.0/) applies to the data made available in this article, unless otherwise stated. 


\section{Background}

Chronic hepatitis $\mathrm{C}$ virus ( $\mathrm{HCV}$ ) infection is one of the main causes of chronic liver disease, and approximately $2.2 \%$ of adults worldwide are infected [1]. In addition, $10-15 \%$ of these cases progress to liver cirrhosis and hepatocellular carcinoma, leading to a fatal outcome [2-4]. The first established therapy for hepatitis $\mathrm{C}$ was interferon (IFN) reported by Hoofnagle et al. in 1986, wherein administration of human recombinant IFN- $\alpha$ resulted in normalization of transaminases in patients with non-A, non-B hepatitis [5]. IFN- $\alpha$ monotherapy (thrice weekly, 6 million international units per day) resulted in sustained virological response (SVR) of only $5 \%$ in resistant cases such as genotype 1 with high viral ribonucleic acid levels; therefore, the development of PEGylated IFN (PEG-IFN) and ribavirin combination therapy contributed to the increase in SVR rates (approximately 42-56\%) [6, 7]. Thus, IFN and its combination therapies significantly decreased the occurrence of hepatocellular carcinoma and improved prognoses [8]. Conversely, in some cases, PEG-IFN and ribavirin combination therapy induces various adverse events including cytopenia, influenza-like, gastrointestinal, and psychiatric symptoms that may require discontinuation of the therapy $[6,7]$.

HCV treatment paradigms have dramatically shifted with the development of direct-acting antivirals (DAAs) that provide SVR rates as high as $80-100 \%$ and with better patient tolerance [9]. However for a portion of IFN-intolerant patients, psychiatric adverse effects have thwarted efforts using DAA therapy. In this report, we present the case of an innate anxiety patient with a history of IFN discontinuation due to psychiatric symptoms and who developed similar symptoms using DAA and ribavirin to treat her $\mathrm{HCV}$ hepatitis. The information summarized is intended for physician awareness of possible drawbacks of IFN-free treatment for HCV infection in patients with underlying psychiatric issues.

\section{Case presentation}

A 49-year-old Japanese woman was presented with chronic hepatitis due to HCV genotype 2 infection. She had a psychiatric history of mild innate anxiety but was not medicated. She was prescribed subcutaneous injection of PEG-IFN $\alpha-2 \mathrm{a}$ at a dose of $180 \mu \mathrm{g}$ per week to treat chronic hepatitis. After initiation of therapy, a lowgrade fever and mild general fatigue were observed. Psychiatric symptoms such as enervation, palpitations, an episode of hyperventilation, and consciousness disturbances with myotonia appeared after the third injection of PEG-IFN $\alpha-2 a$. It was impossible to decide if the symptoms were IFN-related or due to a somatization disorder elicited by anxiety, but the IFN therapy was discontinued and followed by administration of etizolam and paroxetine hydrochloride hydrate treatment by psychiatrists. Although the symptoms gradually improved, it took 3 months for the patient to completely recover (Fig. 1); the anti-anxiety medications were continued for a prolonged period. While waiting for approval of DAA therapy, the patient was administered liver supporting therapies: oral ursodeoxycholic acid and glycyrrhizinate. Upon approval, the patient was administrated with IFNfree sofosbuvir and ribavirin combination therapy. She was 57 years at this time point and 8 years had elapsed since the PEG-IFN therapy. The patient remained diagnosed with chronic hepatitis, as she showed a low score of 2.50 in the fibrosis-4 index [10] and aspartate aminotransferase-to-platelet ratio index [11] was 0.731 . Unexpectedly, psychiatric symptoms similar to those observed with IFN and consciousness disturbance attacks appeared 4 days after treatment initiation. Initially, psychiatrists attributed the symptoms to epileptic seizures, and sodium valproate was administrated. However, her symptoms did not improve, and the patient was admitted for further observation and treatment.

Physical examination was unremarkable. The liver and spleen were not palpable, and her bowel sounds were normal. Anemia and jaundice were not seen in palpebral conjunctiva or bulbar conjunctiva. Flapping tremor and leg edema were absent. Abnormal neurological finding were not detected. The patient denied alcohol and/or drug abuse. Upon admission, the patient was administrated etizolam and paroxetine for anxiety disorder, ursodeoxycholic acid and glycyrrhizinate for chronic hepatitis, and metoprolol and enalapril for chronic heart failure after a surgical operation for endocardial cushion defect. Other than a mild increase in serum aspartate and alanine aminotransferase levels due to sodium valproate administration, no abnormal laboratory findings, including ammonium or glycemic levels that might induce consciousness disturbances, were found (Table 1). There was no evidence for HBV and HIV co-infection. Furthermore, the patient's electroencephalogram and brain magnetic resonance imaging findings were normal (Fig. 2a-c). These results indicated no evidence of infection or hepatic or drug-induced encephalopathy. In addition, the patient had stable vital signs and communicated well even during the psychiatric attacks unless prompted about hepatitis related topics (which would not have been the case if she was suffering from epileptic seizures). Based on the clinical picture, psychiatrists confirmed a diagnosis of somatization disorder induced by anxiety from antiviral therapy. Sodium valproate, sofosbuvir, and ribavirin were discontinued, and her symptoms gradually disappeared after 3 months. Antianxiety medication was continued for treatment of the somatization disorder; the patient continued to receive liver supporting therapies because of a mild increase in 


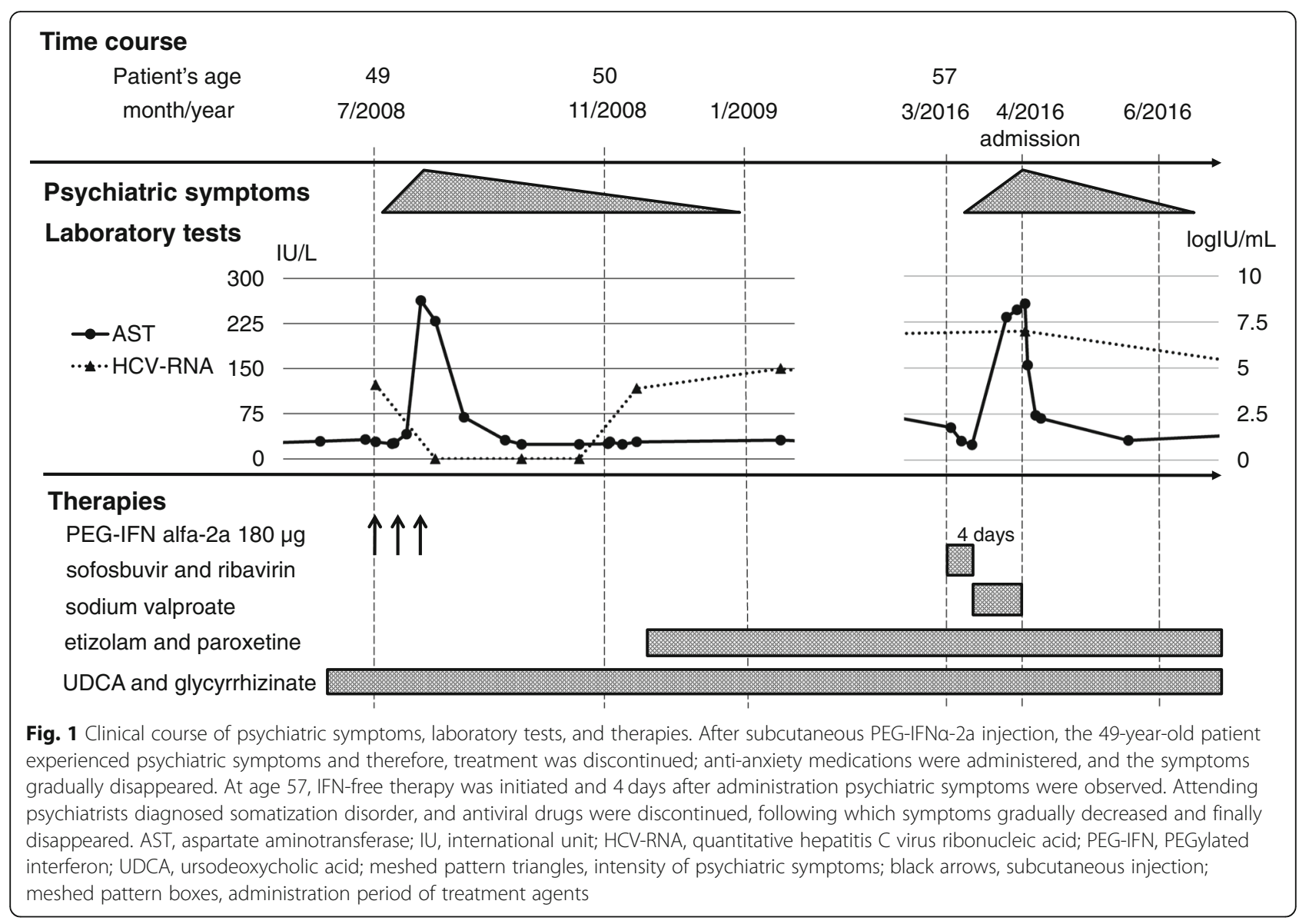

serum aspartate and alanine aminotransferase levels; interruption of antiviral therapy showed no clearance of $\mathrm{HCV}$. With the combination of mental health support from psychiatrists, we are planning to retry an alternate DAA regimen without ribavirin.

\section{Discussion and conclusions}

A meta-analysis of $\mathrm{HCV}$ patients demonstrated evidence for high incidence rates of depression and/or anxiety even in untreated patients [12]. It is well known that IFN therapy precipitates psychiatric symptoms such as depression, irritability, anxiety, agitation, loss of appetite, fatigue, sleep disturbance, and impaired cognition; it is difficult to distinguish underlying symptoms from IFNrelated ones [13]. Risk factors for IFN-related psychiatric symptoms include the following: high dose of IFN, older age, history of organic brain syndrome, current psychiatric diseases, or depression or insomnia, drug abuse, and disease or therapy anxiety [14]. IFN-related psychiatric adverse events lead to discontinuation of therapy or hospital admission in $10 \%$ of cases, whereas $30 \%$ of cases continue IFN therapy with supportive therapy such as anti-depressant or anti-anxiety medication $[15,16]$. In several patients with psychiatric symptoms, intolerance to IFN resulted in the future of HCV elimination.

DAA therapy, on the other hand, is associated with high SVR rates and better patient tolerance, especially for psychiatric symptoms, as reported in a phase 3 study that excluded patients with underlying psychiatric disorders [9]. Ledipasvir and sofosbuvir combination therapy showed SVR rates of 99\%, with no discontinuation owing to adverse events and no treatment-related depression [17]. Similarly, high SVR rate and fewer adverse events were reported with DAA combination therapy with ribavirin for $\mathrm{HCV}$ genotype 2 patients [18]. However, in a phase 4 , open-label study, $6.1 \%$ of patients with liver cirrhosis, reported depression and an equal rate of insomnia in a patient population where $35 \%$ suffered from underlying depression, 30\% from underlying anxiety or anxiety disorder, and 10\% from alcohol abuse [19]. Takeda et al. reported a mild increase in depression in the first 4 weeks after administration of DAAs, which recovered within 12 weeks [20], as revealed by the Beck Depression Inventory scores, which are calculated by a 21-question multiple-choice self-application instrument to assess the severity of depression [21]. The authors suggested that anxiety associated with antiviral treatment 
Table 1 Laboratory data on admission with psychiatric symptoms after sofosbuvir and ribavirin combination IFN-free therapy

\begin{tabular}{|c|c|c|c|c|c|}
\hline Hematology & & Normal Value & Biochemistry & & Normal Value \\
\hline Leukocyte count (/mm³) & 3370 & $3300-8600$ & Total Protein (g/dl) & 7.2 & $6.6-8.1$ \\
\hline Erythrocyte count $\left(\times 10^{4} / \mathrm{mm}^{3}\right)$ & 450 & $386-492$ & Albumin (g/dl) & 3.8 & $4.1-5.1$ \\
\hline Hemoglobin (g/dl) & 13.7 & $11.6-14.8$ & Serum sodium $(\mathrm{mEq} / \mathrm{l})$ & 140 & $138-145$ \\
\hline Hematocrit (\%) & 42.3 & $35.1-44.4$ & Serum potassium(mEq/l) & 3.8 & $3.6-4.8$ \\
\hline Platelet count $\left(\times 10^{4} / \mathrm{mm}^{3}\right)$ & 10.2 & $15.8-34.8$ & Serum chloride(mEq/l) & 104 & $101-108$ \\
\hline \multirow[t]{2}{*}{ Coagulation test } & & & Serum IP (mg/dl) & 3.1 & $2.5-4.5$ \\
\hline & & & Serum calcium (mg/dl) & 9.5 & $8.8-10.1$ \\
\hline Prothrombin time (\%) & 93 & $70-130$ & Total bilirubin (mg/dl) & 0.6 & $0.4-1.5$ \\
\hline PT-INR & 1.04 & 1.0 & Direct bilirubin (mg/dl) & 0.1 & $<0.3$ \\
\hline \multirow[t]{2}{*}{ Tumor marker } & & & AST(IU/I) & 255 & $13-30$ \\
\hline & & & ALT(IU/I) & 434 & $7-23$ \\
\hline a-fetoprotein (ng/ml) & 3 & $<9.5$ & $\mathrm{LDH}(\mathrm{IU} / \mathrm{I})$ & 252 & $124-222$ \\
\hline AFP-L3(\%) & $<0.5$ & $<10.0$ & ALP(IU/I) & 376 & $106-322$ \\
\hline \multirow[t]{2}{*}{ Viral marker } & & & GGT(IU/I) & 81 & $9-32$ \\
\hline & & & Blood urea nitrogen $(\mathrm{mg} / \mathrm{dl})$ & 12 & $8-20$ \\
\hline $\mathrm{HCV}-\mathrm{Ab}$ & positive & negative & Creatinine (mg/dl) & 0.60 & $0.46-0.79$ \\
\hline HCV serotype & 2 & & Fasting blood sugar (mg/dl) & 132 & \\
\hline \multirow[t]{2}{*}{ HCV-RNA (loglU/ml) } & 7.0 & negative & Serum ammonia $(\mu l / d l)$ & 47 & $12-66$ \\
\hline & & & C-reactive protein (mg/dl) & 0.01 & $<0.15$ \\
\hline $\mathrm{HBsAg}$ & negative & negative & Thyroid hormone & & \\
\hline \multirow[t]{3}{*}{ HIV-Ab } & negative & negative & & & \\
\hline & & & Free triiodothyronine $(\mathrm{pg} / \mathrm{ml})$ & 3.5 & $2.3-4.0$ \\
\hline & & & Free thyroxine (ng/dl) & 1.3 & $0.9-1.7$ \\
\hline
\end{tabular}

Abnormal values are given in bold type

PT-INR, international normalized ratio of prothrombin time; AFP-L3, Lens culinaris agglutinin a-reactive a-fetoprotein; HCV-Ab, hepatitis C virus-antibody; HCV-RNA, quantitative hepatitis $C$ virus-ribonucleic acid; HBsAg, hepatitis B surface antigen; HIV-Ab, human immunodeficiency virus-antibody; IP, inorganic phosphorus; AST, aspartate aminotransferase; ALT, alanine aminotransferase; LDH, lactate dehydrogenase; ALP, alkaline phosphatase; GGT, gamma-glutamyl transpeptidase
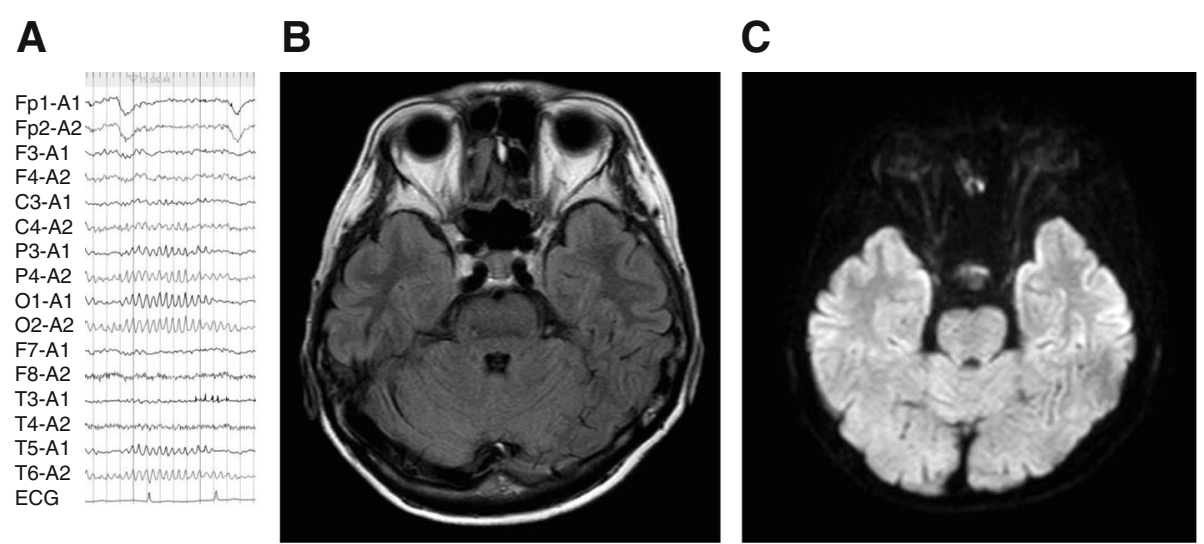

Fig. 2 Imaging findings on admission with psychiatric symptoms after interferon-free therapy. Electroencephalogram showed 10-11 Hz with an irregular unsteady a wave dominant in the occipital lobe and without paroxysmal abnormality (a). Brain magnetic resonance imaging in fluidattenuated inversion recovery $(\mathbf{b})$ and diffusion-weighted imaging $(\mathbf{c})$ revealed normal findings, and drug-induced encephalopathy was not developed 
might worsen depression scores, regardless of the regimen, which is consistent with the clinical course observed in our case. Although, to our knowledge, DAAs do not directly affect the central nervous system, Volpato et al. reported DAAs may have mild neurotoxicity in patients with LC, because of increased relative delta power in the electroencephalogram at the end of treatment with DAAs [22]. Conversely, Sundberg et al. reported no increase in depression scores on other self-rating scales after DAA therapy [23]. Further studies are required to determine whether DAAs affect the central nervous system and manifest psychiatric symptoms, since patients with underlying psychiatric disorders are sensitive to psychiatric adverse events associated with DAA therapy.

Furthermore, ribavirin may worsen the psychiatric symptoms. Ribavirin combination therapy with both PEGIFN [6] and DAA [24] significantly increased not only anemia, but also psychiatric symptoms such as fatigue and insomnia compared with PEG-IFN or DAA monotherapy.

In conclusion, psychiatric disease is common among patients with chronic $\mathrm{HCV}$ infection, and those undergoing IFN-based treatment, but our case signals the possibility of psychiatric effects with oral DAA regimens as well. Therefore, close monitoring is necessary for patients who have psychiatric risk factors similar to IFNrelated psychiatric symptoms, such as history of depression, insomnia, or anxiety to disease or medication, and who are undergoing IFN-free therapy, especially ribavirin combination regimens.

\section{Abbreviations \\ DAA: Direct-acting antiviral; HCV: Hepatitis C virus; IFN: Interferon; PEG- \\ IFN: PEGylated interferon; SVR: Sustained virological response}

\section{Acknowledgements}

Not applicable.

\section{Authors' contributions}

AS, KK, NS, KT, and KM contributed to treatment for hepatitis. NF, HW, TSu, and TSo contributed to diagnosis and treatment for psychiatric symptoms. AS wrote the manuscript. MT, HK, SY, and ST critically revised the manuscript for important intellectual content. All authors read and approved the final manuscript.

\section{Authors' information}

Not applicable.

\section{Funding}

The authors have no funding to report.

\section{Availability of data and materials}

All data generated or analysed during this study are included in this published article.

\section{Ethics approval and consent to participate}

This case report did not require the review by the Institutional Review Board of Graduate School of Medical and Dental Sciences, Niigata University.

\section{Consent for publication}

A written informed consent was obtained for publication from the patient.

\section{Competing interests}

The authors declare that they have no competing interests.

\section{Author details}

'Division of Gastroenterology and Hepatology, Graduate School of Medical and Dental Sciences, Niigata University, 1-757 Asahimachidori, Chuo-ku, Niigata 951-8510, Japan. ${ }^{2}$ Division of Psychiatry, Graduate School of Medical and Dental Sciences, Niigata University, 1-757 Asahimachidori, Chuo-ku, Niigata 951-8510, Japan.

Received: 29 November 2017 Accepted: 6 June 2019

Published online: 13 June 2019

\section{References}

1. Global Burden Of Hepatitis C Working Group. Global burden of disease (GBD) for hepatitis C. J Clin Pharmacol. 2004;44:20-9.

2. Seeff $L B$, Hoofnagle $J H$. Appendix: the National Institutes of Health consensus development conference Management of Hepatitis C 2002. Clin Liver Dis. 2003;7:261-87.

3. Yoshida H, Shiratori $Y$, Moriyama M, et al. Interferon therapy reduces the risk for hepatocellular carcinoma: national surveillance program of cirrhotic and noncirrhotic patients with chronic hepatitis C in Japan. IHIT study group. Inhibition of Hepatocarcinogenesis by interferon therapy. Ann Intern Med. 1999;131:174-81.

4. Cardoso AC, Moucari R, Figueiredo-Mendes C, et al. Impact of peginterferon and ribavirin therapy on hepatocellular carcinoma: incidence and survival in hepatitis C patients with advanced fibrosis. J Hepatol. 2010;52:652-7.

5. Hoofnagle JH, Mullen KD, Jones DB, et al. Treatment of chronic non-a, non$B$ hepatitis with recombinant human alpha interferon. A preliminary report. N Engl J Med. 1986;315:1575-8.

6. Fried MW, Shiffman ML, Reddy KR, et al. Peginterferon alfa-2a plus ribavirin for chronic hepatitis C virus infection. N Engl J Med. 2002;347:975-82.

7. Manns MP, MCHutchison JG, Gordon SC, et al. Peginterferon alfa-2b plus ribavirin compared with interferon alfa-2b plus ribavirin for initial treatment of chronic hepatitis C: a randomised trial. Lancet. 2001;358:958-65.

8. Ikeda K, Saitoh S, Arase Y, et al. Effect of interferon therapy on hepatocellular carcinogenesis in patients with chronic hepatitis type C: a long-term observation study of 1,643 patients using statistical bias correction with proportional hazard analysis. Hepatology. 1999;29:1124-30.

9. Maan R, van Tilborg M, Deterding K, et al. Safety and effectiveness of directacting antiviral agents for treatment of patients with chronic hepatitis $C$ virus infection and cirrhosis. Clin Gastroenterol Hepatol. 2016;14:1821-30.

10. Vallet-Pichard A, Mallet V, Verkarre V, et al. FIB-4: an inexpensive and accurate marker of fibrosis in HCV infection. Comparison with liver biopsy and fibrotest. Hepatology. 2007:46:32-6.

11. Wai CT, Greenson JK, Fontana RJ, et al. A simple noninvasive index can predict both significant fibrosis and cirrhosis in patients with chronic hepatitis C. Hepatology. 2003;38:518-26.

12. Schaefer $M$, Capuron L, Friebe $A$, et al. Hepatitis $C$ infection, antiviral treatment and mental health: a European expert consensus statement. J Hepatol. 2012;57:1379-90.

13. Pinto EF, Andrade C. Interferon-related depression: a primer on mechanisms, treatment, and prevention of a common clinical problem. Curr Neuropharmacol. 2016;14:743-8.

14. Okanoue T, Sakamoto $\mathrm{S}$, Itoh $\mathrm{Y}$, et al. Side effect of high-dose interferon therapy for chronic hepatitis C. J Hepatol. 1996;25:283-91.

15. Hosoda S, Takimura H, Shibayama M, Kanamura H, Ikeda K, Kumada H. Psychiatric symptoms related to interferon therapy for chronic hepatitis $\mathrm{C}$ : clinical features and prognosis. Psychiatry Clin Neurosci. 2000;54:565-72.

16. McNutt MD, Liu S, Manatunga A, et al. Neurobehavioral effects of interferon$a$ in patients with hepatitis-C: symptom dimensions and responsiveness to paroxetine. Neuropsychopharmacology. 2012;37:1444-54.

17. Afdhal N, Zeuzem S, Kwo P, et al. Ledipasvir and sofosbuvir for untreated HCV genotype 1 infection. N Engl J Med. 2014;370:1889-98.

18. Zeuzem S, Dusheiko GM, Salupere R, et al. Sofosbuvir and ribavirin in HCV genotypes 2 and 3. N Engl J Med. 2014;370:1993-2001.

19. Ho SB, Monto A, Peyton A, et al. Efficacy of Sofosbuvir plus ribavirin in veterans with hepatitis $C$ virus genotype 2 infection, compensated cirrhosis, and multiple comorbidities. Clin Gastroenterol Hepatol. 2017;15:282-8.

20. Takeda K, Noguchi R, Namisaki T, et al. Therapeutic effect of dual oral therapy with daclatasvir and asunaprevir for chronic HCV patient with depression. Kanzo (Journal of the Japan Society of Hepatology). 2016;57: 496-8 in Japanese. 
21. Beck AT, Ward $\mathrm{CH}$, Mendelson $\mathrm{M}$, et al. An inventory for measuring depression. Arch Gen Psychiatry. 1961;4:561-71.

22. Volpato $S$, Montagnese $S$, Zanetto A, et al. Neuropsychiatric performance and treatment of hepatitis $C$ with direct-acting antivirals: a prospective study. BMJ Open Gastroenterol. 2017;4(1):e000183.

23. Sundberg I, Lannergård $\mathrm{A}$, Ramklint $\mathrm{M}$, et al. Direct-acting antiviral treatment in real world patients with hepatitis $C$ not associated with psychiatric side effects: a prospective observational study. BMC Psychiatry. 2018;18:157.

24. Foster GR, Afdhal N, Roberts SK, et al. Sofosbuvir and Velpatasvir for HCV genotype 2 and 3 infection. N Engl J Med. 2015;373:2608-17.

\section{Publisher's Note}

Springer Nature remains neutral with regard to jurisdictional claims in published maps and institutional affiliations.

Ready to submit your research? Choose BMC and benefit from:

- fast, convenient online submission

- thorough peer review by experienced researchers in your field

- rapid publication on acceptance

- support for research data, including large and complex data types

- gold Open Access which fosters wider collaboration and increased citations

- maximum visibility for your research: over $100 \mathrm{M}$ website views per year

At $\mathrm{BMC}$, research is always in progress.

Learn more biomedcentral.com/submissions 